\title{
Tumor necrosis factor- $\alpha$ induces caspase-independent cell death in human neutrophils via reactive oxidants and associated with calpain activity
}

\author{
Hao-Cheng Chen, Chih-Jan Wang, Chun-Liang Chou, Shu-Min Lin, Chien-Da Huang, \\ Ting-Yu Lin, Chun-Hua Wang, Horng-Chyuan Lin, Chih-Teng Yu, Han-Pin Kuo \& \\ Chien-Ying Liu* \\ Division of Pulmonary Oncology and Interventional Bronchoscopy, Department of Thoracic Medicine, \\ Chang-Gung Memorial Hospital, 199, Tun-Hwa North Road, Taipei, 105, Taiwan
}

Received 2 November 2005; accepted 13 December 2005

(C) 2006 National Science Council, Taipei

Key words: apoptosis, calpain, caspase, neutrophil, oxidant, tumor necrosis factor

\section{Summary}

Apoptosis mediated by caspase activation is important in the neutrophil homeostasis and resolution of tissue inflammation. Paradoxically, our previous study demonstrated that broad-spectrum caspase inhibition augmented tumor necrosis factor (TNF)- $\alpha$-induced cell death in the human neutrophils. Therefore, we further explored the mechanisms related to the caspase-independent cell death in the neutrophils. The cell apoptosis/necrosis was determined by annexin $\mathrm{V}$ and propidium iodide dual staining in flow cytometry. Their morphological changes were observed under light microscopy. Fluorogenic substrates were used to measure the intracellular oxidative reactions and the activities of proteinases, calpains. Calpain inhibitors and antioxidants were used to elucidate the relationship of calpains and oxidants with the neutrophil cell death. Our results verified the caspase-independent cell death pathway in the zVAD-sensitized, TNF- $\alpha$ stimulated neutrophils. Furthermore, the cell death was accompanied with increased calpain and oxidative activities in the cells. Calpain inhibitors, zLLY, as well as anti-oxidants, catalase and DMSO, were able to attenuate the cell death in the zVAD-sensitized, TNF- $\alpha$-induced neutrophils. Pretreating the neutrophils with G-CSF or GM-CSF was not able to reduce the cell death. These results demonstrate that, in human neutrophils, TNF- $\alpha$-induces a caspase-independent cell death signal, which is related to calpain and oxidative activities and cannot be rescued by the growth factor-related signaling mechanism.

\section{Introduction}

Neutrophils are essential components of the natural immune system and have been implicated in the pathogenesis of a wide variety of human diseases [1]. Neutrophils are constantly produced in large numbers in the bone marrow [2]. Their lives are short in circulation, but can increase several folds once they enter infected or inflamed tissues full of inflamma-

*To whom correspondence should be addressed. Fax: + 886-33272474; E-mail: cyliu01@adm.cgmh.org.tw

HC Chen and CJ Wang contributed equally to the preparation of this manuscript as first authors. tory mediators $[3,4]$. Thus, the similar numbers of cells need to die within a defined time period and the activation of death signals of neutrophils is critical in order to maintain cellular homeostasis under physiologic and pathological conditions [5, 6]. Furthermore, neutrophil apoptosis and safe removal by phagocytic cells are important to prevent neutrophils from releasing their cytotoxic contents and causing severe tissue damages [5].

Spontaneous neutrophil apoptosis is mediated by the caspase- 3 activity [7]. Activation of Fas, a death receptor constitutively expressed in circulating mature human neutrophils [8], also activates 
caspase- 3 activity and induces neutrophil apoptosis [9]. In addition to the Fas ligand-Fas system, the tumor necrosis factor- $\alpha$ (TNF- $\alpha)$-TNF receptor system is also an important participant in the inflammatory responses. TNF- $\alpha$ is an important cytokine mediator involved in a variety of inflammatory, infectious and malignant human diseases, including acute respiratory distress syndrome (ARDS), pneumonia and tumor cell invasion and migration [10]. TNF- $\alpha$ can induce neutrophil apoptosis at earlier times of incubation [11]. Isolated mature, circulating human neutrophils are sensitive to both Fas and TNF receptor agonistinduced cell death [12].

There is increasing evidence for caspaseindependent mechanisms of apoptotic cell death [13]. These novel caspase-independent forms of cell death with distinguished differences from the classically described apoptotic or necrotic cell processes have been reported in a variety of human cell lines and primary cells, including fibroblast, epithelial cells, lymphocyte, and lymphoma cells [14-16]. The distinctions between apoptotic vs. necrotic and programmed vs. non-programmed cell death have become blurred [17]. Terms such as paraptosis [18] and aponecrosis [19] have been proposed for this specific type of cell death. In addition, human neutrophils were shown to undergo cell death in the absence of classical apoptotic or necrotic characteristics under specific stimulation $[20,21]$ and in patients with sepsis, arthritis or chronic granulomatous diseases [22, 23].

Dysregulation of neutrophil apoptosis has been an implication for human diseases. For examples, accelerated neutrophil apoptosis was observed in patients with acquired immunodeficiency syndrome (AIDS) and may contribute to the secondary infection. [24]. On the contrary, elimination of neutrophils has been regarded as a pivotal component in limiting tissue injury and facilitating the resolution of inflammation [25]. With continuous emergence of novel proteins and mechanisms that modify the caspase-dependent and -independent processes, human neutrophils represent a physiologically relevant cell for the investigation of death pathways. Furthermore, the study of neutrophil apoptosis and the elucidation of its molecular mechanisms may lead to identify novel therapeutic targets in the related human diseases.

The molecules unique to the caspase-independent pathway in neutrophils are still unknown at present.
In our previous study, we had built an in vitro model using peripheral blood-isolated human neutrophils pretreated with general caspase inhibitors to study the caspase-independent mechanism in the cells. We clearly demonstrated the apoptotic-like and necrotic-like cell death in the TNF- $\alpha$-stimulated neutrophils pretreated with general caspase inhibitors [22]. It has been reported that reactive oxidative activity and calpains, one of the cysteine protease families, are involved in neutrophil apoptosis [26]. Studies have also shown that excessive production of granulocyte colony-stimulating factor (G-CSF) and granulocyte/macrophage colony-stimulating factor (GM-CSF), two important neutrophil survival factors, is often observed in inflammatory responses [27, 28]. Therefore, we investigated the activities and the potential roles of oxidative reaction and calpains in the zVADsensitized, TNF- $\alpha$-stimulated neutrophils. The protective effects of G-CSF and GM-CSF in the neutrophils were also examined to further explore the caspase-independent apoptosis mechanism.

\section{Methods}

\section{Reagents}

All cell culture media and supplements were purchased from Life Technologies (Grand Island, NY). Recombinant human TNF- $\alpha$, G-CSF and GM-CSF were purchased from R\&D Systems (Minneapolis, MN). The cell-permeable, irreversible, broad-spectrum caspase inhibitors Boc-D and zVAD, the cell-permeable calpain inhibitor, ZLLY, the fluorogenic caspase substrate, Ac-DEVDAMC, and fluorogenic calpain substrate, BocLev-Met-CMAC were obtained from Calbiochem (La Jolla, CA). FITC-conjugated annexin V (annexin V-FITC) was purchased from BD PharMingen (San Diego, CA). 2', 7'-dichlorofluorescin-diacetate (DCFH-DA), and propidium iodide (PI) were obtained from Sigma (St. Louis, MO).

\section{Isolation of circulating mature human neutrophils}

Peripheral blood was obtained from normal adult donors under protocols approved by the Human Subjects Review Committee, Chang-Gung Memorial Hospital. Following erythrocyte-sedimentation 

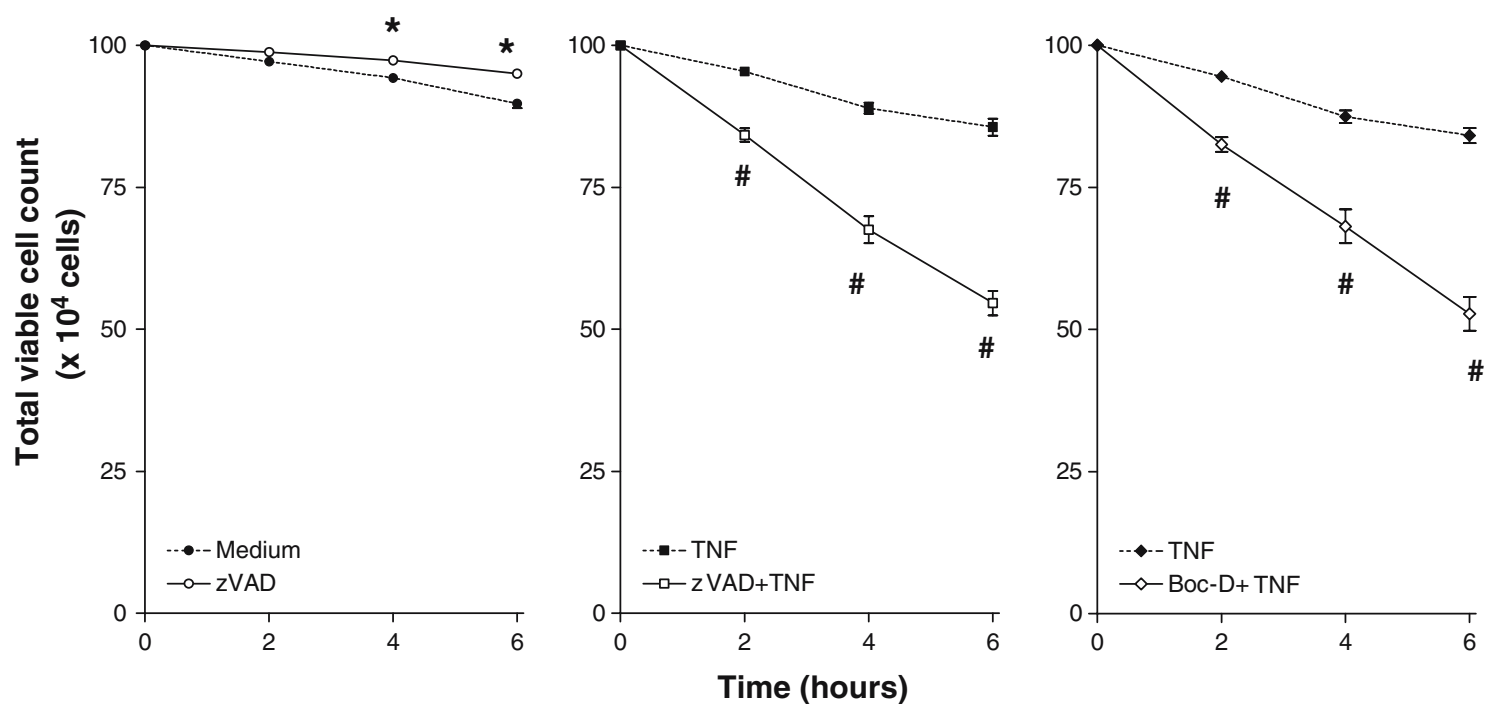

Figure 1. Broad spectrum caspase inhibitors, zVAD and Boc-D, attenuated constitutive neutrophil cell death but paradoxically augmented the TNF- $\alpha$-induced neutrophil cell death. One million freshly isolated mature human neutrophils $\left(5 \times 10^{6}\right.$ cells $\left./ \mathrm{ml}\right)$ were preincubated with or without the cell-permeable, broad-spectrum caspase inhibitors, zVAD (100 $\mu \mathrm{M})$ or Boc-D (100 $\mu \mathrm{M})$, for $1 \mathrm{~h}$. Subsequently, at time 0 , neutrophils were stimulated with TNF- $\alpha(10 \mathrm{ng} / \mathrm{ml})$ vs. buffered saline. The total number of viable neutrophils that remained, as defined by trypan blue dye-exclusion, was determined by a hematocytometer at the indicated times. Data shown are means \pm SEM and are representative of five experiments performed in triplicates. ${ }^{*} p<0.05$, compared to the neutrophils without $\mathrm{zVAD}$ at the corresponding time-point. \#p<0.05, compared to TNF- $\alpha$ only at the corresponding time-point.

with hexastarch (Abbott laboratories, Abbott Park, IL), neutrophils were separated from the leukocyte fraction over a discontinuous gradient, Ficoll-Paque Plus (Amersham Pharmacia Biotech, density $1.077,450 \times g, 25^{\circ} \mathrm{C}, 30 \mathrm{~min}$ ), as previously described [29, 30]. After lysis of contaminating erythrocytes with buffered ammonium chloride, purified neutrophils were resuspended in a roundbottom polypropylene tube in RPMI medium supplemented with $10 \%$ heat-inactivated FBS and antibiotics. The purity and viability of isolated neutrophils were consistently more than $98 \%$. Unless indicated otherwise, $1 \times 10^{6}$ neutrophils at the concentration of $5 \times 10^{6}$ cells $/ \mathrm{ml}$ were used for each sample throughout our study.

\section{Cell death assessment by light microscopy}

At pre-defined time-points, total neutrophil viable cell counts that remained under various treatment conditions were determined by trypan blue dye-exclusion with a hemacytometer. In parallel, cytospin slides were prepared, stained with DiffQuick (Baxter, McGaw Park, IL), and examined by light microscopy for morphological changes.

\section{Cell death assessment by flow cytometry}

Annexin V-FITC binds to exposed phosphatidylserine on early apoptotic [31] cells and PI gains entry into necrotic cells [32]. Utilizing these agents, early apoptotic and primary/secondary necrotic neutrophils were quantitatively determined by flow cytometry. Briefly, neutrophils were cultured under a specified condition in a humidified $\mathrm{CO}_{2}$ (5\%)-incubator at $37^{\circ} \mathrm{C}$. At a predetermined time-point, neutrophils were resuspended in $100 \mu 1$ of binding buffer $(140 \mathrm{mM} \mathrm{NaCl}, 2.5 \mathrm{mM}$ $\mathrm{CaCl}_{2}, 1.5 \mathrm{mM} \mathrm{MgCl}_{2}$, and $10 \mathrm{mM}$ HEPES, pH 7.4) containing annexin V-FITC $(20 \mu \mathrm{g} / \mathrm{ml})$ and PI $(2 \mu \mathrm{g} / \mathrm{ml})$ for $15 \mathrm{~min}$ at room temperature. Samples were kept on ice and analyzed immediately with an EPICS XL-II flow cytometer (Beckman Coulter, Fullerton, CA).

\section{Caspase-3 activity assay}

Neutrophils $\left(2 \times 10^{6}\right.$ cells in $400 \mu \mathrm{l}$ of supplemented RPMI medium) at a predetermined time-point post-treatment were washed with PBS and lysed in $100 \mu \mathrm{l}$ of buffer (10 mM potassium phosphate, 
$1 \mathrm{mM}$ EDTA, 0.5\% Triton X-100, 2 mM PMSF, $10 \mu \mathrm{g} / \mathrm{ml}$ leupeptin, $10 \mu \mathrm{g} / \mathrm{ml}$ pepstatin $\mathrm{A}$, and $10 \mathrm{mM}$ DTT) for $10 \mathrm{~min}$ on ice. After centrifugation $\left(15,000 \mathrm{~g}, 20 \mathrm{~min}, 4^{\circ} \mathrm{C}\right)$, protein concentration of the supernatant was determined with the BCA Protein Assay Reagent (Pierce, Rockford, IL), following manufacturer's instructions. Subsequently, $40 \mu \mathrm{g}$ of the sample was diluted to a final volume of $200 \mu \mathrm{l}$ with the assay buffer $(50 \mathrm{mM}$ HEPES, $10 \%$ sucrose, $0.1 \%$ CHAPS, and $10 \mathrm{mM}$ DTT) containing the fluorogenic caspase-3-preferred substrate Ac-DEVD-AMC $(100 \mu \mathrm{M})$ and incubated for $2 \mathrm{~h}$ at $30^{\circ} \mathrm{C}$ in a 96-well plate. Fluorescence was determined (excitation: $360 \mathrm{~nm}$, emission: $460 \mathrm{~nm}$ ) with a CytoFluor series 4000 plate reader (Applied Biosystems, Foster City, CA). Background fluorescence was determined in wells containing the assay buffer only.

\section{Cell death assessment by DNA fragmentation assays}

Internucleosomal DNA fragmentation was quantitatively assayed by antibody-mediated capture and detection of cytoplasmic mono- and oligonucleosome-associated histone-DNA complexes (Cell Death Detection ELISA plus kit, Roche Molecular Biochemicals, Mannheim, Germany) that accumulated in dying neutrophils with intact cell membrane. Briefly, neutrophils $\left(1 \times 10^{4}\right.$ cells in $200 \mu \mathrm{l}$ of supplemented RPMI medium) at a predetermined time-point post-treatment were washed, resuspended in $200 \mu \mathrm{l}$ of the lysis buffer supplied by the manufacturer, and incubated for $30 \mathrm{~min}$ at room temperature. After pelleting nuclei $(200 \times g, 10 \mathrm{~min}), 20 \mu \mathrm{l}$ of the supernatant (cytoplasmic fraction) was used in the ELISA, following the manufacturer's standard protocol. Finally, absorbance at 405 and $490 \mathrm{~nm}$ (reference wavelength), upon incubating with a peroxidase substrate for $5 \mathrm{~min}$, were determined with a microplate reader (Bio-Tec Instruments, Inc., Winooski, VT). Signals in the wells containing the substrate only were subtracted as background.

\section{Calpain activity assay}

Neutrophils $\left(1 \times 10^{6}\right.$ cells in $200 \mu$ of supplemented RPMI medium) in specified treatment conditions, cultured in a 48-well plates, were incubated in
RPMI containing $50 \mu \mathrm{M}$ of cell-permeable fluorogenic calpain substrate, Boc-Lev-Met-CMAC. Samples were incubated at $37^{\circ} \mathrm{C}$ and intermittently measured at $1 \mathrm{~h}$ interval for $6 \mathrm{~h}$ excited at $360 \mathrm{~nm}$ and at emission of $460 \mathrm{~nm}$ with a CytoFluor series 4000 plate reader.

\section{Measurement of intracellular oxidative activity}

Intracellular oxidative metabolism of neutrophils was assessed using the cell-permeable, fluorogenic DCFH-DA as described [30]. Briefly, the neutrophil sample $\left(1 \times 10^{6}\right.$ cells in $200 \mu$ of supplemented RPMI medium) was supplemented with DCFH-DA $(5 \mu \mathrm{M}) 30 \mathrm{~min}$ before the completion of a predetermined duration of incubation under a specified condition. Upon intracellular hydrolysis and subsequent oxidization, fluorescent DCF was generated. Cells were washed with ice-cold PBS and resuspended in $0.5 \mathrm{ml}$ PBS supplemented with $1 \%$ FBS. Accumulation of intracellular fluorescence in live cells was determined by flow cytometry.

\section{Statistical analysis}

Quantitative data are expressed as means \pm SEM. For normally distributed data, $t$-test or paired $t$-test was used to evaluate the differences between sets. For non-normally distributed data, Mann-Whitney $U$-test was used. GraphPad Prism (version 3.0, GraphPad Software, San Diego, CA) was used for all statistical analyses. Statistical significance was defined as $p<0.05$.

Figure 2. zVAD sensitized neutrophils to the TNF- $\alpha$-induced cell death in a time and dose-dependent manner. Neutrophils were preincubated with $\mathrm{zVAD}$ at the indicated concentrations $(0,5,25,100 \mu \mathrm{M})$ for $1 \mathrm{~h}$. At time 0 , TNF- $\alpha$ was supplemented to the various final concentrations $(0,0.1,1,0 \mathrm{ng} / \mathrm{ml})$. Cell death was analyzed at $2 \mathrm{~h}$ intervals for $6 \mathrm{~h}$ by dualparameter flow cytometry utilizing FITC-conjugated annexin $\mathrm{V}$ (annexin V-FITC) and propidium iodide (PI). (a) On the flow cytometric scatter graphs, the left lower quadrant represents remaining live cells. The right lower quadrant represents the population of early apoptotic cells. The right upper quadrant represents the accumulation of both late apoptotic cells. The percentages of cells in each of these quadrants are indicated in the representative graph. (b and c) Data shown are means \pm SEM and are representative of five experiments performed in triplicates. ${ }^{*} p<0.05$, compared to the neutrophils treated with next lower concentration of zVAD or TNF at the corresponding time-point. $\# p<0.05$, compared to the neutrophils at $2 \mathrm{~h}$ earlier time-point. 
(a)

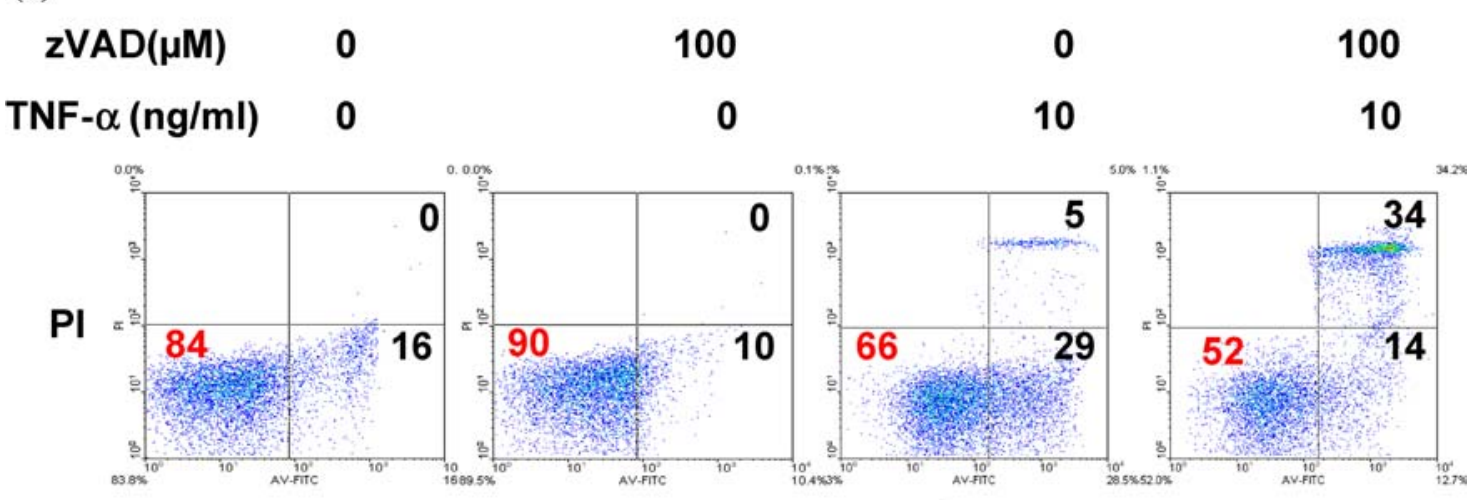

Annexin V-FITC
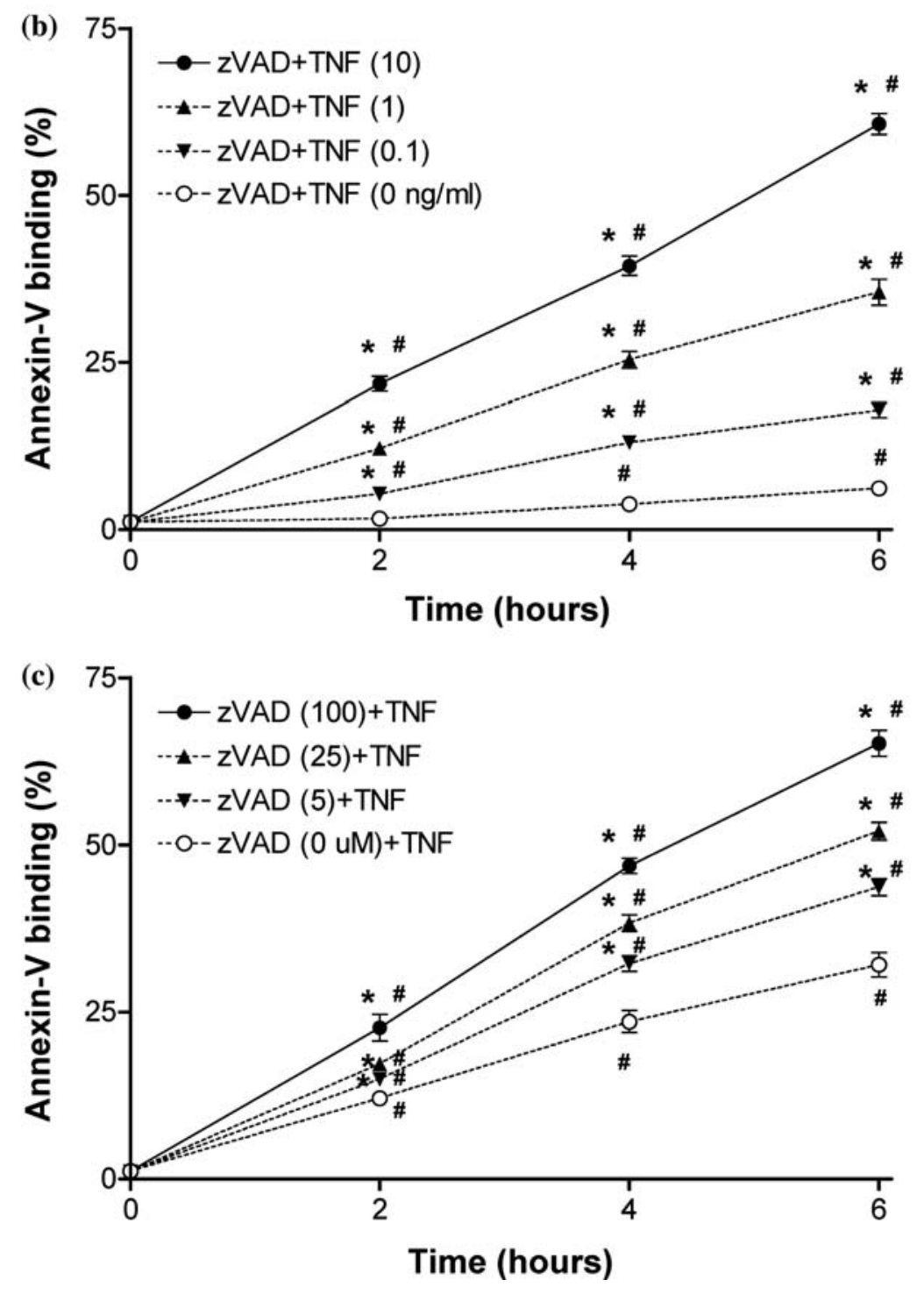

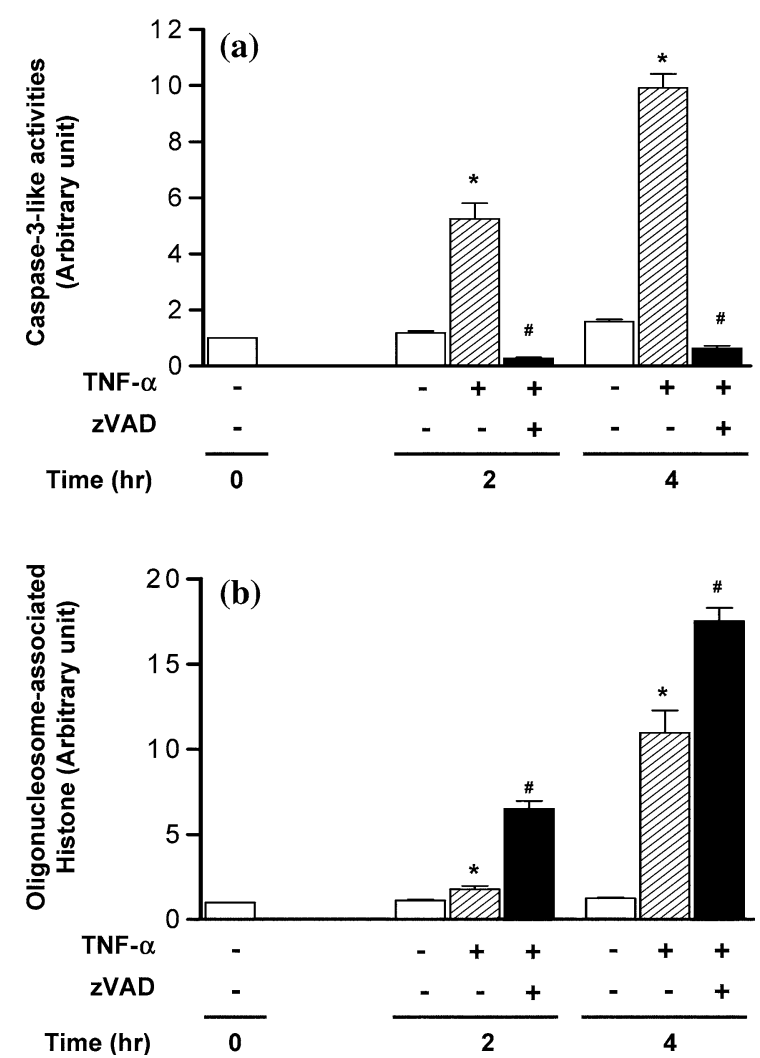

Figure 3. Caspase-3-like activity, but not the fragmented oligonucleosome, was abrogated by the broad-spectrum caspase inhibitor in the zVAD-sensitized, TNF- $\alpha$-stimulated neutrophils. (a) Cleavage of the caspase-3-preferred fluorogenic substrate, Ac-DEVD-AMC, was measured in whole cell lysates prepared from neutrophils preincubated with or without zVAD $(100 \mu \mathrm{M})$ for $1 \mathrm{~h}$ and then stimulated with or without TNF- $\alpha(10 \mathrm{ng} / \mathrm{ml})$ for two additional $\mathrm{h}$. Results shown represent means \pm SEM of three experiments. ${ }^{*} p<0.05$, compared to unstimulated neutrophils at $2 \mathrm{~h}$. (b) In separate experiments, internucleosomal DNA fragmentation was quantitatively determined by assessment of cytoplasmic mono- and oligo-nucleosome-associated histone accumulation in the membrane-intact cells at the indicated time-points. Results shown represent means \pm SEM, $n=5$. ${ }^{*} p<0.05$, compared to the unstimulated neutrophils at the corresponding times; $\# p<0.05$, compared to the neutrophils stimulated with $\mathrm{TNF}-\alpha$ only at the corresponding times.

\section{Results}

TNF- $\alpha$ induced neutropil cell apoptosis, which was augmented by broad-spectrum caspase inhibitors

In the time-course experiments, zVAD failed to inhibit but instead augmented TNF- $\alpha$-induced neutrophil cell death, determined by viable cell counts (Figure 1). Furthermore, the sensitization of neutrophils to TNF- $\alpha$-induced cell death was not limited to zVAD. Another broad-spectrum, cell-permeable caspase inhibitor, Boc-D, also produced a similar effect (Figure 1). Additionally, pretreatment with zVAD sensitized the neutrophils to the TNF $\alpha$-induced cell death over $6 \mathrm{~h}$ in a timeand dose-dependent manner (Figure 2a-c). The cleavage of a fluorogenic substrate for caspase-3 proteases, Ac-DEVD-AMC, was abrogated in the cell lysates prepared from neutrophils incubated with zVAD and TNF- $\alpha$ (Figure 3a), which conforms the effect of caspase-3 inhibition. Intriguingly, this capase- 3 inhibition did not attenuate cell death as what was expected, instead, zVAD enhanced DNA fragmentation, as demonstrated in the cytoplasmic oligonucleosome-associated histone assay (Figure 3b). Under light microscopy, neutrophils incubated with zVAD alone appeared normal morphology whereas TNF- $\alpha$-stimulated neutrophils exhibited classic features of apoptosis. Nonetheless, significant numbers of neutrophils concurrently incubated with zVAD and TNF- $\alpha$ showed cell shrinkage and nuclei condensation, as apoptotic-like alterations, as well as faint stained and swollen phenotype, as features of necrotic-like changes (Figure 4).

\section{Calpain and oxidative activities contributed to the zVAD sensitized, TNF- $\alpha$-stimulated neutrophil cell death}

To further explore the caspase-independent mechanism in neutrophil cell death, mediators related to the neutrophil apoptosis were studied. We found that the cleavage of a fluorogenic substrate for calpain proteases, Boc-Lev-Met-CMAC, was increased in the zVAD-sensitized, TNF- $\alpha$-stimulated neutrophils, which could be abrogated by the calpain inhibitor, zLLY (Figure 5a). The corresponding cell death mediated by these treatments can also be observed, as determined by the annexin $\mathrm{V}$ binding assay (Figure 5b). The oxidative activities along with cell death in the neutrophils treated with zVAD and TNF- $\alpha$ were also upregulated (Figure 6a, b). Abrogating the oxidative activities with oxygen radical scavengers, catalase and DMSO, was able to synergistically attenuate the zVAD sensitized, TNF- $\alpha$-stimulated neutrophil cell death (Figure 6a, b), suggesting the contribution of calpain and oxidative activities in the caspase-independent cell death in the neutrophils. 

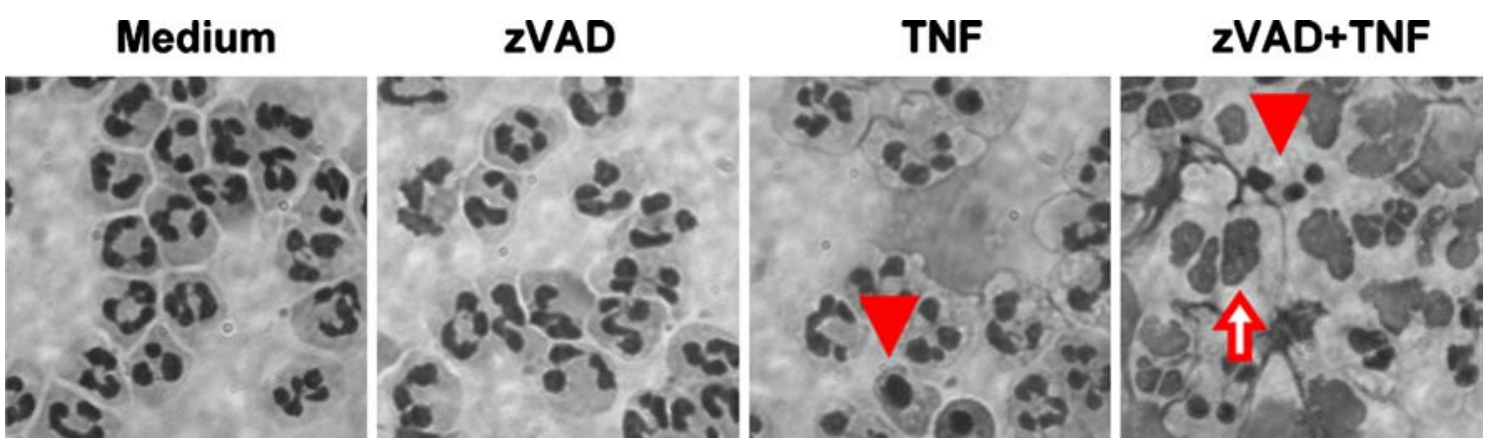

Figure 4. zVAD-sensitized, TNF- $\alpha$-stimulated neutrophils underwent cell death characterized by the emergence of apoptotic-like and necrotic-like cells. Neutrophils were preincubated with or without zVAD $(100 \mu \mathrm{M})$ for $1 \mathrm{~h}$. Subsequently, at time 0 , neutrophils were stimulated with TNF $\alpha(10 \mathrm{ng} / \mathrm{ml})$ vs. buffered saline. Diff-Quick-stained cytocentrifuge preparations of neutrophils preincubated with or without zVAD and harvested at $4 \mathrm{~h}$ after the addition of TNF $\alpha$ or buffered saline were examined by light microscopy (1000× magnification). Note that TNF- $\alpha$ alone induced classic apoptotic nuclear changes. zVAD-sensitized, TNF $\alpha$ stimulated neutrophils frequently displayed apoptotic-like cell shrinkage and nuclear fragmentation and condensation (closed arrow). In addition, necrotic-like changes with the feature of cell and nuclear swelling were observed (open arrow).

Neutrophil-related growth factors, G-CSF and GM$C S F$ failed to rescue the zVAD-sensitized, TNF- $\alpha$ induced cell death

Neutrophil-sensitive growth factors, G-CSF and GM-CSF, were known to activate anti-apoptotic bcl2 family such as A1 and A20 in neutrophils, which could inhibit the caspase activation and further prolong the neutrophil survival. It would be interesting to know whether the rescuing effects of these factors exist to counter-act the cell death in the zVAD-sensitized, TNF- $\alpha$-stimulated neutrophils. In flow cytometry, our data revealed that there was no significant difference in the fractions of annexin V-negative and PI-negative, annexin $\mathrm{V}$-positive and PI-negative, and annexin V-positive and PI-positive cells in the zVAD-sensitized, TNF- $\alpha$-stimulated neutrophils with or without the pretreatment of G-CSF or GM-CSF (Figure 7a). Using flow cytometry, we found no significant difference in the cell death rate in the presence of absence of G-CSF or GM-CSF (Figure 7b). The finding that G-CSF and GM-CSF could not protect the neutrophils from death induced by zVAD and TNF- $\alpha$ suggested that a dominant cell death pathway, other than the caspase cascade, which also bypass the neutrophil survival signals, was activated.

\section{Discussion}

In the present study, we verified that broadspectrum caspase inhibition paradoxically augmented the TNF- $\alpha$-stimulated neutrophil cell death. We further demonstrated that the cell death was related to the intracellular oxidative activity and calpain activation, as exhibited by the fluorogenic substrate assay and pharmacologic inhibition study. Neutrophil survival factors, G-CSG and GM-CSF were not able to rescue this type of cell death.

An increasing number of evidences have shown that a caspase-independent cell death mechanism exists upon agonistic death receptor stimulation. Broad-spectrum caspase inhibitors were able to sensitize the death receptor agonist-induced cell death in the transformed cell lines [33-35]. Human lymphocytes [36], macrophages [37] and lymphoma cells [38] are the primary human cell types in which caspase-independent cell death has been documented. The observation that PMA-activated neutrophil cell death was accompanied with minimal induction of caspase-3-like activities and insensitive to broad-spectrum caspase inhibition [39] suggest that the mechanism for executing caspase-independent cell death exist in the circulating mature human neutrophils. Our previous observation that the sensitizing effect imposed by broad-spectrum caspase inhibition was for TNF $\alpha$ induced but not for constitutive or Fas agonistinduced neutrophil cell death further complicated the caspase-independent cell death mechanisms in human neutrophils.

The underlying mechanisms that contribute to the observed differences in the fate of neutrophils remain unclear. The specific features of cell death 

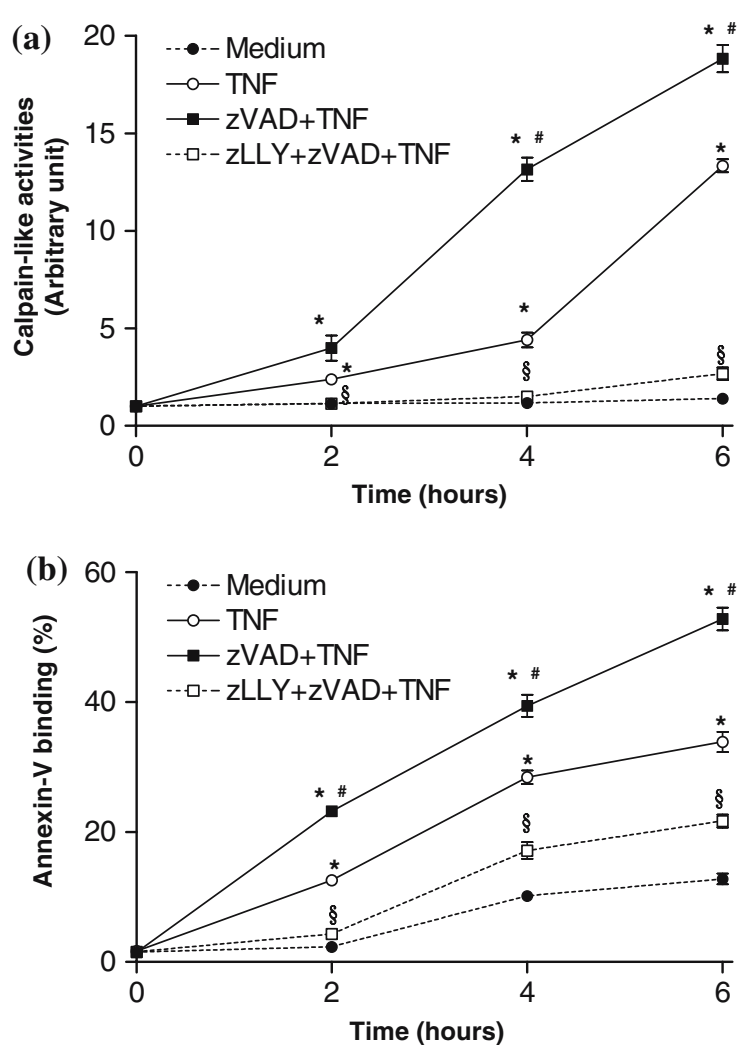

Figure 5. Calpain-like activity contributed to the cell death response in the zVAD-sensitized, TNF- $\alpha$-stimulated neutrophils. Freshly isolated neutrophils $\left(1 \times 10^{6}\right.$ cells, $\left.200 \mu \mathrm{l}\right)$ were preincubated with or without the calpain inhibitor, zLLY, $30 \mathrm{~min}$ before the addition of $\mathrm{zVAD}(100 \mu \mathrm{M}$, for $1 \mathrm{~h})$. Subsequently, at time 0 , neutrophils were stimulated with TNF- $\alpha$ $(10 \mathrm{ng} / \mathrm{ml})$ vs. buffered saline. The intracellular calpain activity and cell death were measured at $2 \mathrm{~h}$ intervals for $6 \mathrm{~h}$ using the fluorogenic substrate (a) and annexin V/PI dual staining, analyzed by flow cytometry (b). Data shown are mean$\mathrm{s} \pm \mathrm{SEM}$ and are representative of five experiments performed in triplicates. ${ }^{*} p<0.05$, compared to the neutrophils without zVAD at the corresponding time-point; $\# p<0.05$, compared to the neutrophils stimulated with TNF- $\alpha$ only; ${ }^{{ }} p<0.05$, compared to the neutrophils stimulated with zVAD $+\mathrm{TNF}-\alpha$.

in the TNF $\alpha$-stimulated neutrophils with broadspectrum caspase inhibition are distinct from that reported in other cell lines undergoing cell death under similar conditions [22]. Unlike 3T3, L929, and U937 cells, which exhibited necrotic-like death processes [33, 34], and NIH3T3 and WEHI-S cells $[13,35]$, which showed dominant apoptotic-like features when co-incubated with TNF- $\alpha$ and broad-spectrum caspase inhibitors, human neutrophils displayed features of both processes. The observations that $\mathrm{zVAD}$ failed to prevent surface externalization of phosphatidylserine prior to lost of plasma membrane integrity [22] and was unable to abrogate oligonucleosomal DNA fragmentation are consistent with the view that there are multiple caspase-dependent and -independent mechanisms by which classical features of apoptosis are mediated and that such mechanisms are triggered in the TNF- $\alpha$-stimulated human neutrophils. Broadspectrum caspase inhibition may switch the pathways in-between [13, 22].

The paradoxical cell death in the TNF- $\alpha$ stimulated neutrophils relates to the intracellular oxidative activities. Studies have shown that endogenously generated oxidants are critically involved in the broad-spectrum caspase inhibitorsensitized, death receptor agonist-induced cell death [33, 34]. The atypical cell death in the neutrophils stimulated by PMA is caspase-independent $[39,40]$ and oxidant- and NADPH oxidase-dependent $[39,41]$. NADPH oxidase system is the dominant machinery for producing intracellular oxidants in the TNF- $\alpha$-activated human neutrophils [42, 43]. Importantly, oxidants produced by this system can participate in the caspase-independent cell death process in neutrophils. Our findings demonstrated that broadspectrum caspase inhibition resulted in sustained oxidant production in the zVAD-sensitized, TNF$\alpha$-stimulated neutrophils, in parallel with the cell death that can be attenuated by catalase and DMSO synergistically. Overall it suggested that oxidant-dependent and caspase-independent mechanisms of cell death are triggered in the $\mathrm{TNF} \alpha$-stimulated neutrophils when caspases are broadly inhibited.

Figure 6. Intracellular oxidative activity contributed to the zVAD-sensitized, TNF- $\alpha$-stimulated neutrophil cell death Freshly isolated neutrophils $\left(1 \times 10^{6}\right.$ cells, $\left.200 \mu \mathrm{l}\right)$ were preincubated with or without the antioxidants, catalase $(300 \mathrm{U} / \mathrm{ml})$ and/or DMSO (1\%, v/v) 30 min before the addition of zVAD $(100 \mu \mathrm{M}$, for $1 \mathrm{~h})$. Subsequently, at time 0 , neutrophils were stimulated with TNF- $\alpha(10 \mathrm{ng} / \mathrm{ml})$. The intracellular oxidative activity and cell death were measured at $6 \mathrm{~h}$ using the DCFH fluorogenic substrate and annexin V/PI dual staining, analyzed by flow cytometry. (a) Flow cytometric graphs shown above are representative of three independent experiments. (b) Quantitative data shown are means \pm SEM and are representative of five experiments performed in triplicates. ${ }^{*} p<0.05$, compared to the neutrophils stimulated with TNF- $\alpha$ only; $\# p<0.05$, compared to the neutrophils stimulated with $\mathrm{zVAD}+\mathrm{TNF}-\alpha ;{ }^{\S} p<0.05$, compared to the zVAD-sensitized, TNF- $\alpha$-stimulated neutrophils pretreated with either calalase or DMSO. 
Catalase+ $\quad$ DMSO+ $\quad$ DMSO+Catalase+

(a) TNF zVAD+TNF zVAD+TNF zVAD+TNF zVAD+TNF
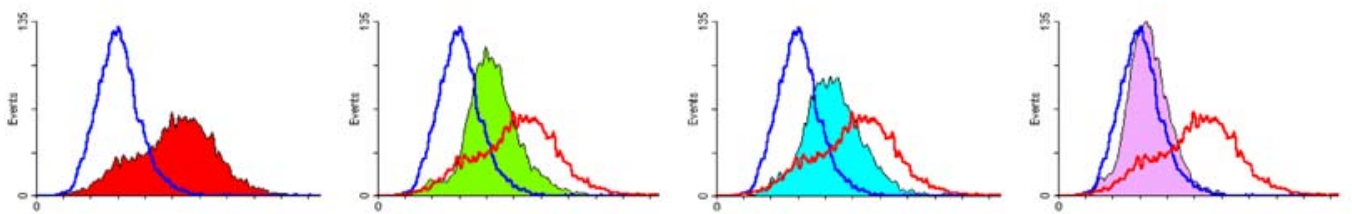

DCF fluorescence (linear scale)

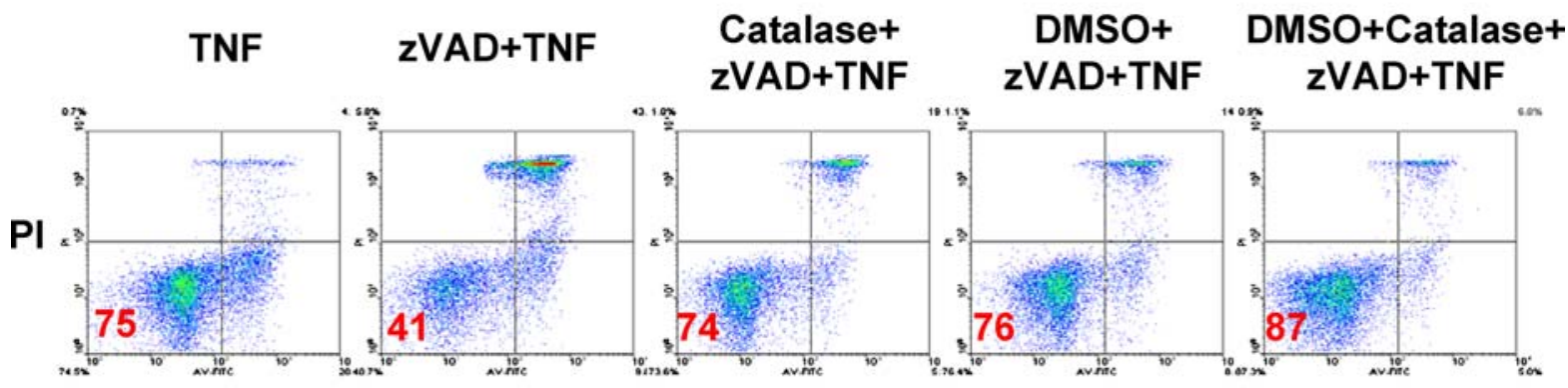

Annexin V-FITC
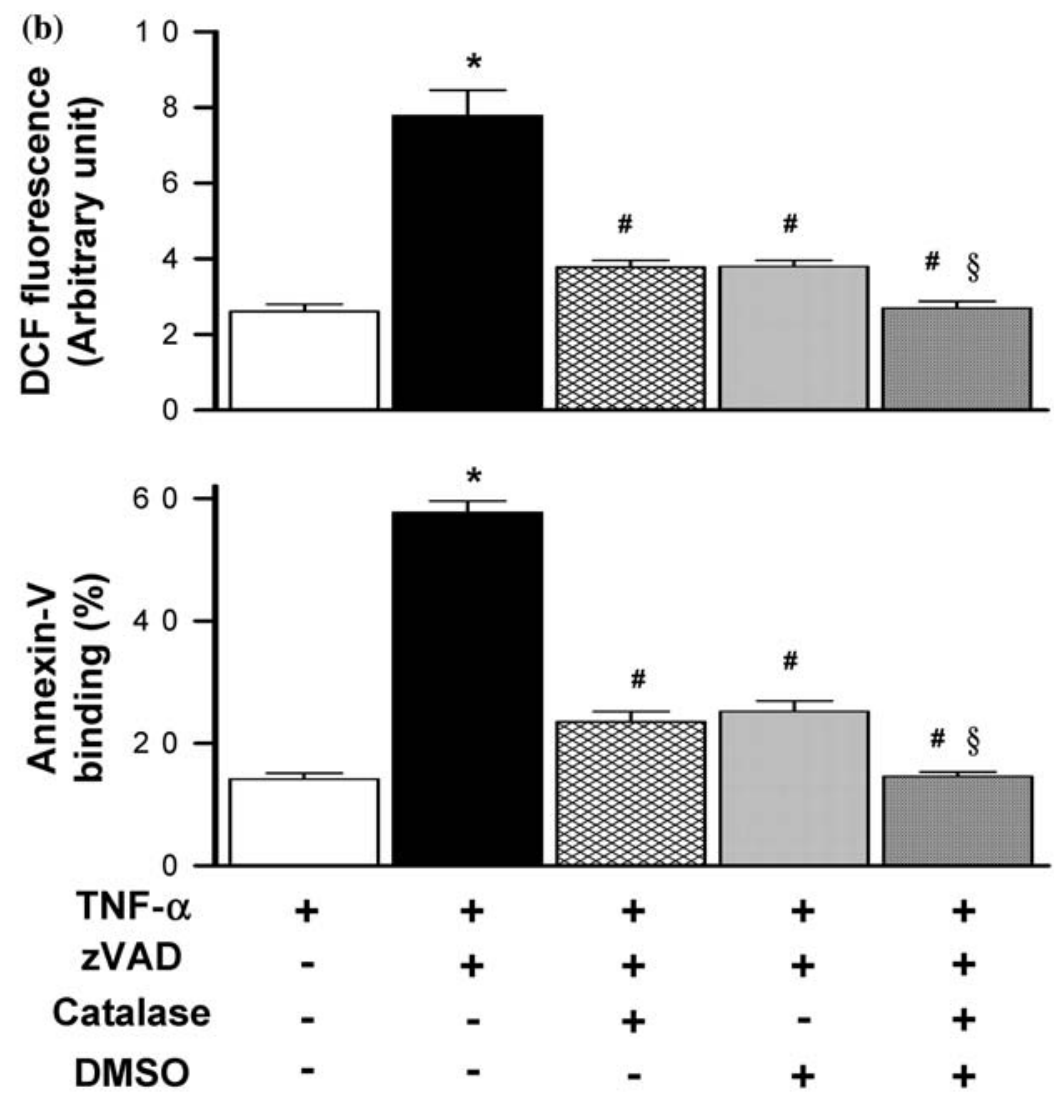


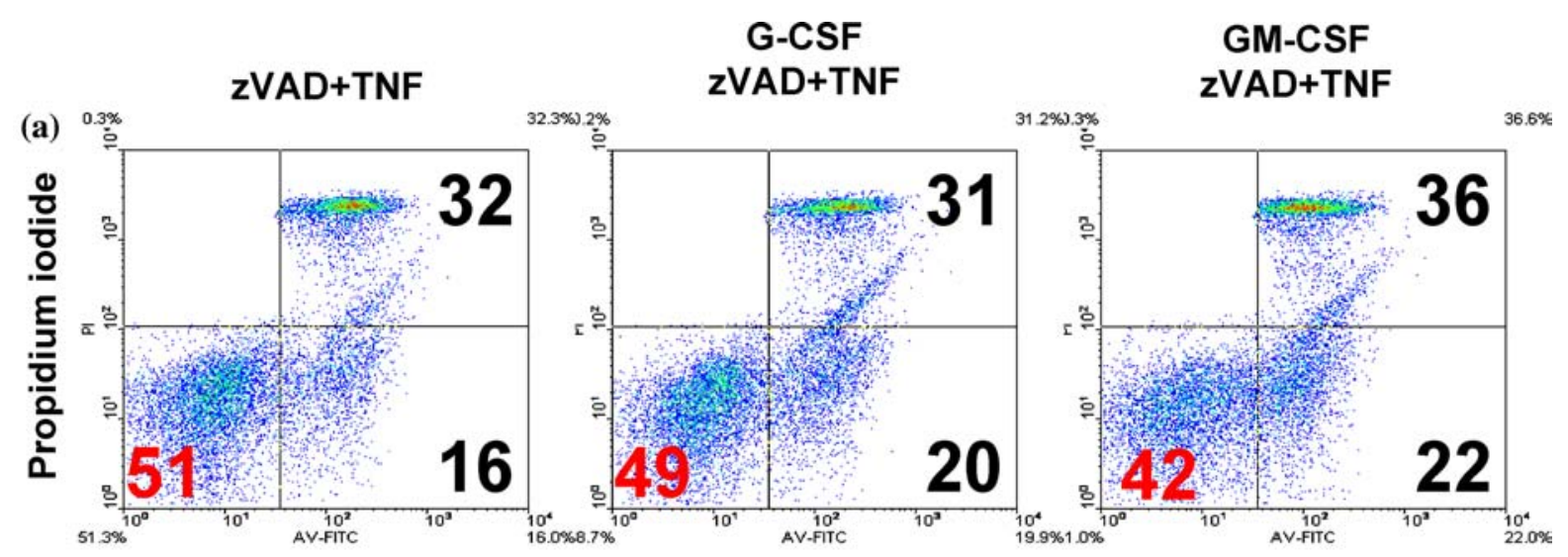

Annexin V-FITC

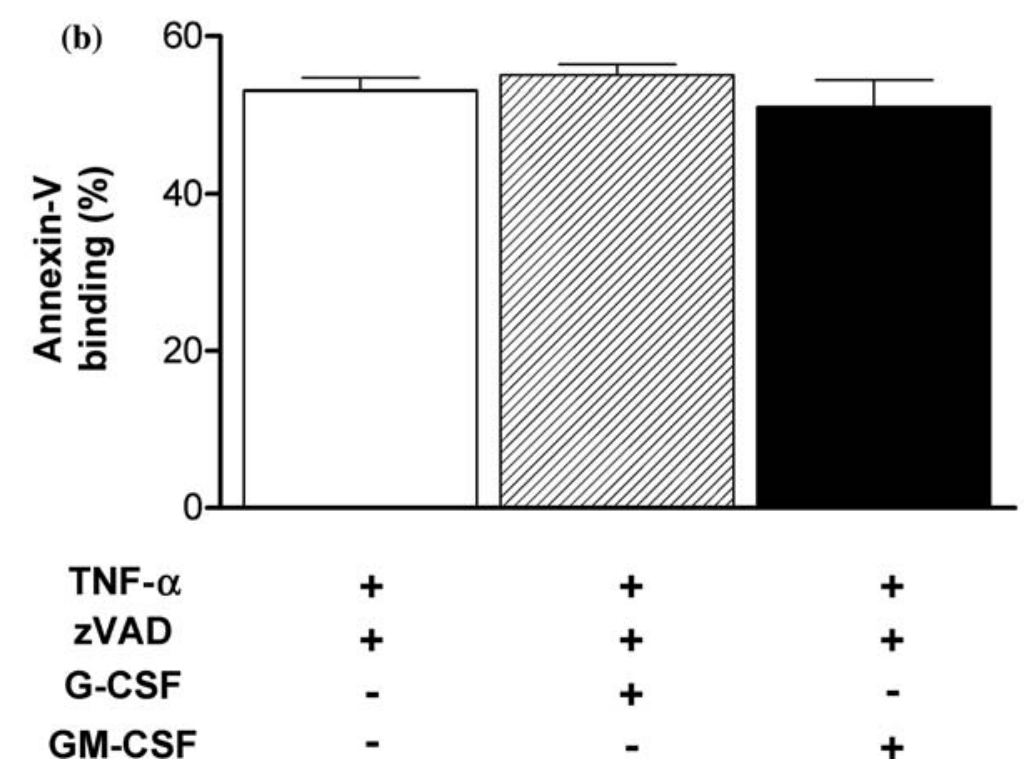

Figure 7. The cell death in the zVAD-sensitized, TNF $\alpha$-stimulated neutrophils could not be rescued by G-CSF and GM-CSF. Freshly isolated neutrophils $\left(1 \times 10^{6}\right.$ cells, $\left.200 \mu \mathrm{l}\right)$ were preincubated with or without G-CSG $(10 \mathrm{ng} / \mathrm{ml})$ or GM-CSF $(10 \mathrm{ng} / \mathrm{ml})$ for $30 \mathrm{~min}$ before the addition of zVAD $(100 \mu \mathrm{M}$, for $1 \mathrm{~h})$. Subsequently, at time 0 , neutrophils were stimulated with TNF- $\alpha$ $(10 \mathrm{ng} / \mathrm{ml})$ vs. buffered saline. The cell death was measured at $6 \mathrm{~h}$ using the annexin V/PI dual staining, analyzed by flow cytometry. (a) Flow cytometric graphs shown above are representative of five independent experiments. (b) Quantitative data shown are means \pm SEM and are representative of five experiments performed in triplicates. No significant difference between groups could be found.

Unlike the role of caspases in the apoptosis cascade, which has been extensively characterized, the role of calpain is less clear. A growing body of works indicates an upstream regulatory role of calpain in cell death. Neutrophil cell death triggered by the translation inhibitor cycloheximide is calpain-dependent [44, 45]. Nevertheless, apoptosis signaled via the Fas antigen proceeds regardless of the presence of calpain inhibitor [45]. Calpain may be responsible for the cleavage of Bcl-xL and, therefore, turn an antiapoptotic molecule into a proapoptotic molecule [46]. Reports have shown that calpain is able to cleave pro-caspase-12 and then activate the caspase cascade, suggesting a cross-talk between the calpain and the caspase proteolytic systems in apoptosis [47]. Additionally, while caspase is only activated in cell apoptosis, calpain is activated in various necrotic and apoptotic conditions [48], indicating that a different, caspase-independent machinery also exists in the 


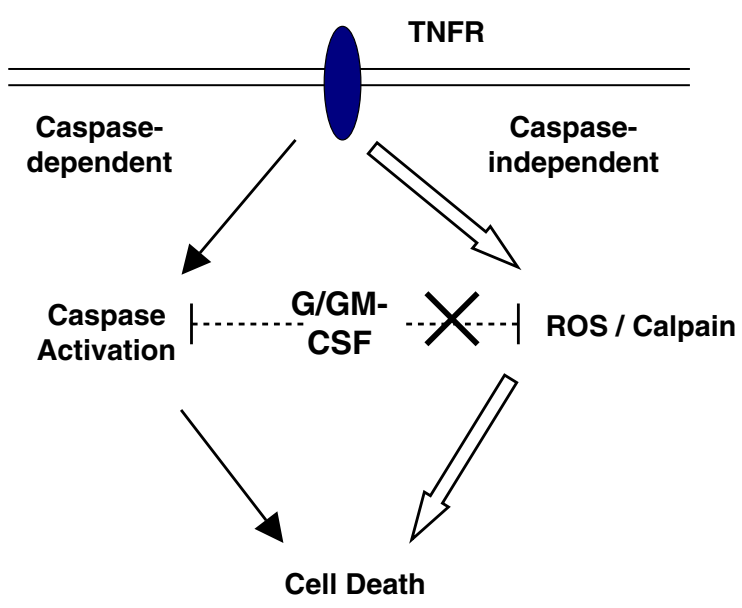

Figure 8. A proposed model of dual death signals in the TNF- $\alpha$-stimulated human neutrophils.

calpain-mediated cell death. Our findings that calpain-like activity was increased in the zVADsensitized, TNF- $\alpha$-stimulated neutrophils, and the cell death was attenuated by calpain inhibitors suggest a pivotal role of calpain in the zVADsensitized, TNF- $\alpha$-stimulated neutrophil death.

Inflammatory mediators, such as G-CSF and GM-CSF slow neutrophil apoptotic process via incompletely understood mechanisms. G-CSF is able to stimulate ERK pathway and activate $\mathrm{NF}-\kappa \mathrm{B}$ signaling system, resulting in an increase in the expression of the neutrophil survival proteins, A1 and Mcl-1 [49, 50]. GM-CSF was reported to delay neutrophil apoptosis by stimulating PI-3 kinase and ERK-dependent pathways, and phosphorylation of $\mathrm{Bad}[50,51]$. Our previous report showed that the activity of NF- $\kappa$ B was not altered in the zVAD-sensitized, TNF- $\alpha$-stimulated neutrophils [22]. In the present study, pre-treatment with G-CSF and GM-CSF failed to rescue the cell death for the zVAD-sensitized, TNF- $\alpha$-stimulated neutrophils, suggesting a dominant effect of the caspase-independent death signaling over the G-CSF and GM-CSF related pro-survival mechanisms (Figure 8).

In conclusion, our data suggest that TNF- $\alpha$ activates both caspase-dependent and -independent cell death mechanisms in human neutrophils. The paradoxical augmentation of cell death in the $\mathrm{TNF} \alpha$-stimulated neutrophils under general caspase inhibition suggests that the caspase-independent mechanisms are normally superseded by the caspase-dependent pathway. When caspase activities are broadly inhibited, TNF- $\alpha$ induces the caspaseindependent mechanisms and cell death ensues. Although the oxidative activity and calpain activation were found to participate in the caspaseindependent neutrophil cell death in our study, the molecular basis and the interaction between the caspase-dependent and -independent cell death mechanisms remain to be elucidated. The biological significance and physiological role of the caspase-independent apoptosis also warrant further study.

\section{Acknowledgements}

The authors would like to thank the National Science Council of Taiwan (NSC 93-2314-182A137 and 94-2314-182A-190) and the Chang-Gung Memorial Hospital, Taiwan (CMRP-32113) for financially supporting this research.

\section{References}

1. Lee A., Whyte M.K. and Haslett C., Inhibition of apoptosis and prolongation of neutrophil functional longevity by inflammatory mediators. J. Leukoc. Biol. 54: 283-288, 1993.

2. Price T.H., Chatta G.S. and Dale D.C., Effect of recombinant granulocyte colony-stimulating factor on neutrophil kinetics in normal young and elderly humans. Blood 88: 335-340, 1996.

3. Dibbert B., Weber M., Nikolaizik W.H., Vogt P., Schoni M.H., Blaser K. and Simon H.U., Cytokine-mediated Bax deficiency and consequent delayed neutrophil apoptosis: a general mechanism to accumulate effector cells in inflammation. Proc. Natl. Acad. Sci. USA 96: 13330-13335, 1999.

4. Hogg J.C., Neutrophil kinetics and lung injury. Physiol. Rev. 67: 1249-1295, 1987.

5. Savill J.S., Wyllie A.H., Henson J.E., Walport M.J., Henson P.M and Haslett C., Macrophage phagocytosis of aging neutrophils in inflammation. J. Clin. Invest. 83: 865-875, 1989.

6. Whyte M.K., Savill J., Meagher L.C., Lee A. and Haslett C., Coupling of neutrophil apoptosis to recognition by macrophages: coordinated acceleration by protein synthesis inhibitor. J. Leukoc. Biol. 62: 195-202, 1997.

7. Pongracz J., Webb P., Wang K., Deacon E., Lunn O.J. and Lord J.M., Spontaneous neutrophil apoptosis involves caspase 3-mediated activation of protein kinase C-delta. J. Biol. Chem. 274: 37329-37334, 1999.

8. Liles W.C., Kiener P.A., Ledbetter J.A., Aruffo A. and Klebanoff S.J., Differential expression of Fas (CD95) and Fas ligand on normal human phagocytes: Implications for the regulation of apoptosis in neutrophils. J. Exp. Med. 184: 429-440, 1996.

9. Huang D.C., Hahne M., Schroeter M., Frei K., Fontana A., Villunger A., Newton K., Tschopp J. and Strasser A., 
Activation of Fas by FasL induces apoptosis by a mechanism that cannot be blocked by Bcl-2 or Bcl-x(L). Proc. Natl. Acad. Sci. USA 96: 14871-14876, 1999.

10. Kimura M., Haisa M., Uetsuka H., Takaoka M., Ohkawa T., Kawashima R., Yamatsuji T., Gunduz M., Kaneda Y., Tanaka N. and Naomoto Y., TNF combined with IFN- $\alpha$ accelerates NF- $\kappa$ B-mediated apoptosis through enhancement of Fas expression in colon cancer cells. Cell Death Differ. 10: 718-728, 2003.

11. Murray J., Barbara J.A., Dunkley S.A., Lpoez A.F., Van Ostade X., Condliffe A.M., Dransfield I., Haslett C. and Chilvers E.R., Regulation of neutrophil apoptosis by tumor necrosis factor-alpha: requirement for TNFR55 and TNFR75 for induction of apoptosis in vitro. Blood 90: 2772-2783, 1997.

12. Salamone G., Giordano M., Trevani A.S., Gamberale R., Vermeulen M., Schettinni J. and Geffner J.R., Promotion of neutrophil apoptosis by TNF-alpha. J. Immunol. 166: 3476-3483, 2001.

13. Lorenzo H.K., Susin S.A., Penninger J. and Kroemer G., Apoptosis inducing factor (AIF): a phylogenetically old, caspase-independent effector of cell death. Cell Death Differ. 6: 516-524, 1999.

14. Bortner C.D. and Cidlowski J.A., Caspase independent/ dependent regulation of $\mathrm{K}^{+}$, cell shrinkage, and mitochondrial membrane potential during lymphocyte apoptosis. J. Biol. Chem. 274: 21953-21962, 1999.

15. Izban K.F., Ergin M., Huang Q., Qin J.Z., Martinez R.L., Schnitzer B., Ni H., Nickoloff B.J. and Alkan S., Characterization of NF-kappaB expression in Hodgkin's disease: inhibition of constitutively expressed NF-kappaB results in spontaneous caspase-independent apoptosis in Hodgkin and Reed-Sternberg cells. Mod. Pathol. 14: 297-310, 2001.

16. Cummings B.S., Kinsey G.R., Bolchoz L.J. and Schnellmann R.G., Identification of caspase-independent apoptosis in epithelial and cancer cells. J. Pharmacol. Exp. Ther. 310: 126-134, 2004.

17. Kitanaka C. and Kuchino Y., Caspase-independent programmed cell death with necrotic morphology. Cell Death Differ. 6: 508-515, 1999.

18. Sperandio S., de Belle I. and Bredesen D.E., An alternative, nonapoptotic form of programmed cell death. Proc. Natl. Acad. Sci. USA 97: 14376-14381, 2000.

19. Formigli L., Papucci L., Tani A., Schiavone N., Tempestini A., Orlandini G.E., Capaccioli S. and Orlandini S.Z., Aponecrosis: morphological and biochemical exploration of a syncretic process of cell death sharing apoptosis and necrosis. J. Cell. Physiol. 182: 41-49, 2000.

20. Takei H., Araki A., Watanabe H., Ichinose A. and Sendo F., Rapid killing of human neutrophils by the potent activator phorbol 12-myristate 13-acetate (PMA) accompanied by changes different from typical apoptosis or necrosis. J. Leukoc. Biol. 59: 229-240, 1996.

21. Liu J., Akahoshi T., Jiang S., Namai R., Kitasato H., Endo H., Kameya T. and Kondo H., Induction of neutrophil death resembling neither apoptosis nor necrosis by ONO-AE-248, a selective agonist for PGE2 receptor subtype 3. J. Leukoc. Biol. 68: 187-193, 2000.

22. Liu C.Y., Takemasa A., Liles W.C., Goodman D.B., Jonas M., Rosen H., Chi E., Winn R.K., Harlan J.M. and Chuang P.I., Broad-spectrum caspase inhibition paradoxically augmented cell death in TNFa-stimulated neutrophils. Blood 101: 295-304, 2003.
23. von Gunten S., Yousefi S., Seitz M., Jakob S.M., Schaffner T., Seger R., Takala J., Villiger P.M. and Simon H.U., Siglec-9 transduces apoptotic and nonapoptotic death signals into neutrophils depending on the proinflammatory cytokine environment. Blood 106: 1423-1431, 2005.

24. Pitrak D.L., Tsai H.C., Mullane K.M., Sutton S.H. and Stevens P., Accelerated neutrophil apoptosis in the acquired immunodeficiency syndrome. J. Clin. Invest. 98: 2714-2719, 1996.

25. Chilvers E.R., Rossi A.G., Murray J. and Haslett C., Regulation of granulocyte apoptosis and implications for anti-inflammatory therapy. Thorax 53: 533-534, 1998.

26. Squier M.K.T., Miller A.C.K., Malkinson A.M. and Cohen J.J., Calpain activation in apoptosis. J. Cell. Physiol. 159: 229-237, 1994.

27. Simon H.U., Neutrophil apoptosis pathways and their modification in inflammation. Immunol. Rev. 193: 101-110, 2003.

28. Akgul C., Moulding D.A. and Edwards S.W., Molecular control of neutrophil apoptosis. FEBS Lett. 487: 318-322, 2001

29. Liu C.Y., Liu Y.H., Lin S.M., Yu C.T., Wang C.H., Lin H.C., Lin C.H. and Kuo H.P., Apoptotic neutrophils undergoing secondary necrosis induce human lung epithelial cell detachment. J. Biomed. Sci. 10: 746-756, 2003.

30. Lin H.C., Wang C.H., Liu C.Y., Yu C.T. and Kuo H.P., Erythromycin inhibits beta2-integrins (CD11b/CD18) expression, interleukin- 8 release and intracellular oxidative metabolism in neutrophils. Respir. Med. 94: 654-660, 2000.

31. Wyllie A.H., Kerr J.F. and Currie A.R., Cell death: the significance of apoptosis. Int. Rev. Cytol. 68: 251-306, 1980.

32. Homburg C.H., de Haas M., von dem Borne A.E., Verhoeven A.J., Reutelingsperger C.P. and Roos D., Human neutrophils lose their surface Fc gamma RIII and acquire Annexin $\mathrm{V}$ binding sites during apoptosis in vitro. Blood 85: 532-540, 1995.

33. Vercammen D., Beyaert R., Denecker G., Goossens V., Van Loo G., Declercq W., Grooten J., Fiers W. and Wandenabeele P., Inhibition of caspases increases the sensitivity of L929 cells to necrosis mediated by tumor necrosis factor. J. Exp. Med. 187: 1477-1485, 1998.

34. Khwaja A. and Tatton L., Resistance to the cytotoxic effects of tumor necrosis factor alpha can be overcome by inhibition of a FADD/caspase-dependent signaling pathway. J. Biol. Chem. 274: 36817-36823, 1999.

35. Foghsgaard L., Wissing D., Mauch D., Mauch D., Lademann U., Bastholm L., Boes M., Elling F., Leist M. and Jaattela M., Cathepsin B acts as a dominant execution protease in tumor cell apoptosis induced by tumor necrosis factor. J. Cell Biol. 153: 999-1010, 2001.

36. Bortner C.D. and Cidlowski J.A., Caspase independent/ dependent regulation of $\mathrm{K}(+)$, cell shrinkage, and mitochondrial membrane potential during lymphocyte apoptosis. J. Biol. Chem. 274: 21953-21962, 1999.

37. Kim S.O., Ono K. and Han J., Apoptosis by pan-caspase inhibitors in lipopolysaccharide-activated macrophages. Am. J. Physiol. Lung Cell Mol. Physiol. 281: L1095L1105, 2001.

38. Izban K.F., Ergin M., Huang Q., Qin J.Z., Martinez R.L., Schnitzer B., Ni H., Nickoloff B.J. and Alkan S., Characterization of NF-kappaB expression in Hodgkin's disease: inhibition of constitutively expressed NF-kappaB results in spontaneous caspase-independent apoptosis in 
Hodgkin and Reed-Sternberg cells. Mod Pathol. 14: 297310, 2001.

39. Fadeel B., Ahlin A., Henter J.I., Orrenius S. and Hampton M.B., Involvement of caspases in neutrophil apoptosis: regulation by reactive oxygen species. Blood 92: 4808-4818, 1998.

40. Nolan B., Duffy A., Paquin L., De M., Collette H., Graziano C.M. and Bankey P., Mitogen-activated protein kinases signal inhibition of apoptosis in lipopolysaccharidestimulated neutrophils. Surgery 126: 406-412, 1999.

41. Lundqvist-Gustafsson H. and Bengtsson T., Activation of the granule pool of the NADPH oxidase accelerates apoptosis in human neutrophils. J. Leukoc. Biol. 65: 196-204, 1999.

42. Bass D.A., Parce J.W., Dechatelet L.R., Szejda P., Seeds M.C. and Thomas M., Flow cytometric studies of oxidative product formation by neutrophils: a graded response to membrane stimulation. J. Immunol. 130: 1910-1917, 1983.

43. Babior B.M., NADPH oxidase: an update. Blood 93: 1464-1476, 1999.

44. Saido T.C., Sorimachi H. and Suzuki K., Calpain: new perspectives in molecular diversity and physiologicalpathological involvement. FASEB J. 8: 814-822, 1994.

45. Squier M.K.T., Sehnert A.J., Sellins K.S., Malkinson A.M., Takano E. and Cohen J.J., Calpain and calpastatin regulate neutrophil apoptosis. J. Cell. Physiol. 178: 311-319, 1999.
46. Nakagawa T., Nakagawa T. and Yuan J., Cross-talk between two cysteine protease families: activation of caspase-12 and calpain in apoptosis. J. Cell Biol. 150: 887-894, 2000.

47. Neumar R.W., Xu Y.A., Gada H., Guttmann R.P. and Siman R., Cross-talk between calpain and caspase proteolytic systems during neuronal apoptosis. J. Biol. Chem. 278: 14162-14167, 2003.

48. Wang K.K.W., Calpain and caspase: can you tell the difference?. Trends Neurosci. 23: 20-26, 2000.

49. Wei S., Liu J.H., Epling-Burnette P.K., Gamero A.M., Ussery D., Pearson E.W., Elkabani M.E., Diaz J.I. and Djeu J.Y., Critical role of Lyn kinase in inhibition of neutrophil apoptosis by granulocyte-macrophage colony-stimulating factor. J. Immunol. 157: 5155-5162, 1996.

50. Klein J.B., Rane M.J., Scherzer J.A., Coxon P.Y., Kettritz R., Mathiesen J.M., Buridi A. and McLeish K.R., Granulocyte-macrophage colony-stimulating factor delays neutrophil constitutive apoptosis through phosphoinositide 3-kinase and extracellular signal-regulated kinase pathways. J. Immunol. 164: 4286-4291, 2000.

51. Suzuki K., Hino M., Hato F., Tatsumi N. and Kitagawa S., Cytokine-specific activation of distinct mitogenactivated protein kinase subtype cascades in human neutrophils stimulated by granulocyte colony-stimulating factor, granulocyte-macrophage colony-stimulating factor, and tumor necrosis factor-alpha. Blood 93: 341-349, 1999. 